\title{
Effect of patient completed agenda forms and doctors' education about the agenda on the outcome of consultations: randomised controlled trial
}

\author{
J F Middleton, R K McKinley, C L Gillies
}

\begin{abstract}
Objective To assess the effect of patient completed agenda forms for the consultation and doctors' education on identifying patients' agendas on the outcome of consultations. Design Randomised controlled trial.

Setting General practices in Leicestershire and Nottinghamshire, United Kingdom.

Participants 46 general practitioners and 976 patients. Interventions Education for general practitioners, with an embedded clustered randomised controlled trial of a patient agenda form.
\end{abstract}

Main outcome measures Number of problems identified, time required to manage each problem, duration of consultations, number of problems raised after the doctor considered the consultation finished ("by the way" questions), and patient satisfaction.

Results Data were available from 45 doctors (98\%) and 857 patients $(88 \%)$. The number of problems identified in each consultation increased by 0.2 (95\% confidence interval 0.1 to 0.4 ) with the agenda form, by 0.3 (0.1 to 0.6$)$ with education, and by 0.5 ( 0.3 to 0.7 ) with both interventions. The time required to manage each problem was not affected. The duration of consultations with the agenda form was increased by 0.9 minutes ( 0.3 to 1.5 minutes) and with the combined intervention by 1.9 minutes (1.0 to 2.8 minutes). Patient satisfaction with the depth of the doctor-patient relationship was increased with the agenda form. The occurrence of "by the way" presentations did not change.

Conclusion A patient completed agenda form before the consultation or general practitioner education about the agenda form, or both, enabled the identification of more problems in consultations even though consultations were longer.

\section{Introduction}

The consultation between a doctor and patient is the core activity of clinical practice. ${ }^{1}$ Anything that improves the quality of the consultation therefore has the potential to improve all aspects of health care. Although identification of why the patient has attended is a key objective of the consultation, ${ }^{2}$ doctors commonly fail to achieve this. ${ }^{34}$ Consequently, patients report that they have been unable to discuss their concerns with their doctors $^{5}$ or have received unwanted prescriptions ${ }^{6}$ or referrals. ${ }^{7}$

Communication in the consultation can be improved by enhancing doctors' ability to facilitate communication or by assisting patients to communicate. Doctors' skills can be enhanced through education. Nevertheless, although educational interventions have been shown to have beneficial effects on the observed behaviours of doctors ${ }^{8-11}$ few have been shown to improve the outcome of consultations with real patients. ${ }^{12}$ Enhancement of patients' ability to participate in the consultation improves communication between the doctor and patient ${ }^{1314}$ and patient outcomes. ${ }^{13-17}$ These studies have used information packages and workshops to develop patient skills that are either condition specific or difficult to disseminate widely. One study, however, showed that simply encouraging obstetrics and gynaecology patients to write down three questions they wished to ask in their consultation reduced their anxiety more than giving them information. ${ }^{18}$ This type of approach has the advantage of being relatively easy to disseminate. One of us previously developed a patient agenda form, to be completed by patients before they consulted with their doctor. ${ }^{19}$ Before giving the form to their doctor, patients write down why they have requested a consultation and what they expect from it. Pilot studies in one practice indicated that the agenda form increased the number of problems identified in consultations but that the consultations were longer. McCann piloted a similar intervention, which also prolonged consultations, but despite patients asking more questions outcomes from the consultation were unchanged. ${ }^{20}$ A second pilot study suggested that educating doctors about patients' agendas reduced the time required to manage each problem. ${ }^{21}$

We examined the effect of the patients' agenda form and educating general practitioners on identifying the patients' agenda on the outcome of consultations. We hypothesised that patient satisfaction, the number of problems identified in the consultation, and the duration of the consultation would be increased by the interventions when used separately but when combined would reduce the time required to manage each problem. Both interventions would reduce the occurrence of "by the way" presentations, when patients raise extra problems after the doctor considers the consultation finished.

\section{Participants and methods}

We invited all general practice principals in Leicestershire and Nottinghamshire to take part in our study. Potential patient participants were those who requested an appointment in one of the study consultations of participating practitioners. Patient partici-

The patient's agenda form and doctor's encounter form are on bmj.com 
pants were told about the study by the receptionist and that they could consult with another doctor or at another time if they wished. Those who accepted an appointment in a study consultation were asked to think of a list of their concerns, to arrive five minutes earlier for the consultation, and to bring spectacles and an interpreter if required. No exclusion criteria were applied. Patient participants were given an information sheet when they attended for their appointment and retold that they could opt out of the study any time by requesting a different appointment or by not completing the study documentation.

\section{Interventions}

\section{Educational workshop}

The aim of the one day educational workshop was to increase doctors' awareness of the patient agenda model of the consultation. ${ }^{22}$ The model focuses on identifying the layers of the patient's agenda (ideas, concerns, expectations, and reasoning), the doctors explicitly reflecting on their own agenda (care of presented and continuing problems, risk factors, and practice and continuing factors), and negotiation of action with the patient. Doctors were given several opportunities to practice applying the model in consultations with simulated patients and were given feedback on their performance. ${ }^{23} 24$

\section{Patient agenda form}

Patients allocated to the consultations using the agenda were asked to complete a patient's agenda form when they arrived for their consultations (see bmj.com).

\section{Study design}

This was a non-preference randomised controlled trial of an education intervention for general practitioners, with an embedded non-preference clustered randomised controlled trial of the agenda form with patient participants clustered within practitioner participants (see bmj.com).

\section{Education}

To maximise recruitment to the study we randomised twice as many doctors to the intervention as were randomised to the control group. The control group was offered the educational intervention after the study ended. We assessed the effect of the educational intervention between these groups of practitioners using all study consultations.

\section{Agenda form}

Half the appointments in each study consultation were randomly allocated the agenda form (intervention) and half no agenda form (control). Patients completed the form and then gave it to the doctor on entering the consulting room. We examined differences between outcomes in each group of patient participants, using all study consultations.

\section{Education and agenda form}

We examined the interaction between education and the agenda form by comparing outcomes between consultations in which the practitioner had been randomised to education or not and in which patients had been randomised to agenda form or not.

\section{Sample size calculation}

Pilot studies of the educational workshop and the agenda form in one practice ${ }^{21}$ indicated that the combination of doctor education and agenda form reduced the time required to manage each problem by 60 seconds, that the standard deviation of the average time to manage each problem was 190 seconds, and the intraclass (within doctor) correlation coefficient of average time spent on each problem was 0.016 . To detect a difference of 60 seconds in the average time spent on each problem, using a randomisation ratio of 2:1, assuming a $5 \%$ significance level and $80 \%$ power, a sample size of 628 patients was required. Estimating an average cluster size of 20 for the full trial, we calculated that with an inflation factor ${ }^{25}$ of 1.3 to account for the design effect, we required a sample size of 816 .

\section{Outcome measures}

\section{Patient satisfaction}

Patient satisfaction was measured using the consultation satisfaction questionnaire, which measures patient satisfaction with individual consultations. ${ }^{26}$ It contains four subscales; general satisfaction, professional care, perceived time, and depth of the doctor-patient relationship. Patients respond using a 5 point Likert scale, and scores are scaled from 0-100, with higher numbers indicating higher satisfaction. Its validity and reliability have been shown. ${ }^{26}{ }^{27}$ The questionnaire was completed by patients after their consultation.

\section{Duration of consultation and number of problems presented}

The doctors completed an encounter form after each consultation, in which they recorded the number of problems identified and the duration of the consultation (using a stop watch, with deductions for interruptions). Each doctor assessed the number of problems independently from the patient's agenda form.

\section{Randomisation and blinding}

JFM generated the randomisation sequences using random number tables. For each doctor, study consultation sessions were arranged with eight appointment slots each for 10 minutes. These slots were randomly allocated to consultations with or without the agenda form. Receptionists were blinded to the randomisation until after the patients had accepted an appointment, when they turned over a card revealing the allocation. Doctors were randomly allocated to the educational intervention or control group, patients were randomly allocated to agenda or no agenda. It was not possible to blind the participating doctors to either the educational intervention or the patients who completed the agenda form.

\section{Statistical analysis}

We analysed the data using Stata version 8.0. Multilevel models were fitted to account for any clustering effects, as patients were clustered within doctor. We show the difference between the control (no education and no agenda form) and the interventions separately and combined. Positive results indicate an increase with the interventions. We also calculated the odds ratios of patients with "by the way" presentations.

\section{Results}

Overall, 187 of the $1230(15.2 \%)$ general practice principals in Leicestershire and Nottinghamshire responded to an invitation (sent between 8 and 30 June, 1995) to participate in the study of whom $103(8.4 \%)$ agreed to take part. Forty six of these were selected at random: 31 were randomly allocated to the education group and 15 to the no education group (fig 1). Table 1 shows the characteristics of the doctors according to group. Data was not recorded for age, sex, or presenting problems of the patients. Patients were recruited to the trial between 30 October and 20 November, 1995. The educational workshop took place on 7 November, 1995. 


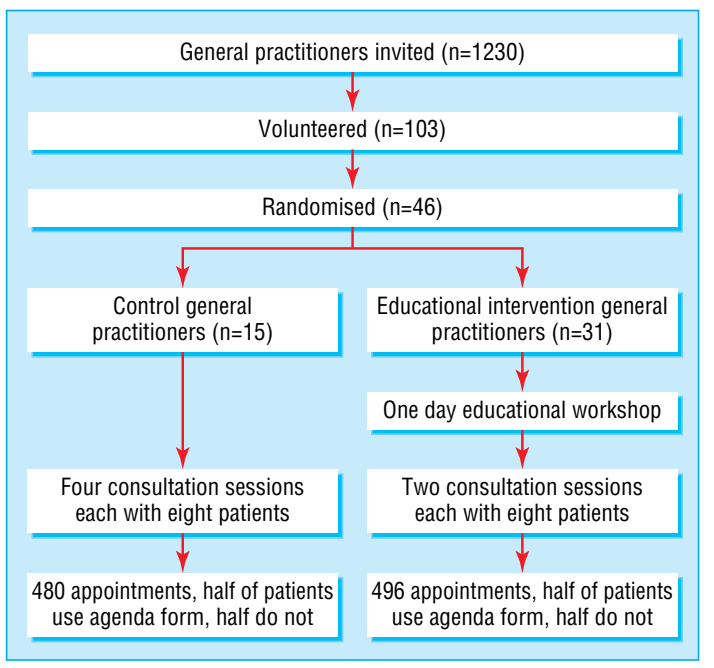

Fig 1 Flow of participants through trial

A total of 976 consultations were included in the study. Data from one doctor in the education arm were lost in the post and five patients $(0.5 \%)$ were not randomised by practice staff, leaving 479 randomised to agenda consultations in the no education arm and 476 randomised to no agenda consultations in the education arm. Within the no education arm, 237 patients were randomised to agenda consultations and 242 patients to no agenda consultations. Within the education arm 236 patients were randomised to agenda consultations and 240 patients were randomised to no agenda consultations. Forty nine patients (5\%) did not attend their appointment, doctor completed data were missing for one appointment $(0.1 \%)$, and data were missing for 48 $(5 \%)$ patients. We had complete data on $857(88 \%)$ patients who were offered study consultations. Availability of data did not differ between the education and no education groups of doctors or between the patients who did or did not complete an agenda form (fig 2).

Table 2 shows the adjusted summary statistics for each outcome variable and the effects of the agenda form and education separately and combined. Control consultations lasted 7.1 minutes $(95 \%$ confidence interval 6.5 to 7.7 minutes). The agenda form significantly increased the duration of consultations by 0.9 minutes $(0.3$ to $1.5 ; \mathrm{P}=0.004)$ and the combined intervention by 1.9 minutes $(1.0$ to $2.8 ; \mathrm{P}<0.001)$. The

Table 1 Comparison of doctor and practice variables in study and control groups. Values are numbers (percentages)

\begin{tabular}{lcc} 
Variables & Study group $(\mathbf{n}=\mathbf{3 1})$ & Control group $(\mathbf{n}=\mathbf{1 5})$ \\
\hline Male & $23(74)$ & $10(67)$ \\
\hline Diploma* & $19(61)$ & $10(67)$ \\
\hline UK graduate & $30(97)$ & $13(87)$ \\
\hline Practice area: & $4(13)$ & $1(7)$ \\
\hline Inner city & $16(52)$ & $10(67)$ \\
\hline Urban & $11(36)$ & $4(27)$ \\
\hline Semirural or rural & & $1(7)$ \\
\hline Doctors' age group (years): & 0 & $3(20)$ \\
\hline $25-29$ & $7(23)$ & $4(27)$ \\
\hline $30-34$ & $6(19)$ & $6(40)$ \\
\hline $35-39$ & $10(32)$ & $1(7)$ \\
\hline $40-44$ & $6(19)$ & 0 \\
\hline $45-49$ & 0 & 0 \\
\hline $50-54$ & $2(7)$ &
\end{tabular}

${ }^{*}$ Membership of the Royal College of General Physicians. educational intervention alone did not significantly change the length of the consultation ( 0.7 minutes, -0.2 to 1.6 minutes). In control consultations with no agenda form and no education the average number of problems identified was 1.7 (1.5 to 1.8). This was significantly increased by both interventions: agenda form by $0.2(0.1$ to $0.4 ; \mathrm{P}=0.007)$ and education by $0.3(0.1$ to 0.6 ; $\mathrm{P}=0.005$ ). Combined, the agenda form and education significantly increased the number of problems identified in each consultation by 0.5 ( 0.3 to $0.7 ; \mathrm{P}<0.001)$. We have no data on agreement between the problems identified by the doctor and the patient. The time spent on each problem was 306 seconds, which was not reduced by either or both interventions. The only change in patient satisfaction was with the depth of the doctor-patient relationship, which was increased by the agenda form (3.0 (0.5 to 5.6); $\mathrm{P}=0.02)$. No change was found in the number of "by the way" presentations.

\section{Discussion}

If patients are encouraged to make their agenda explicit in consultations, doctors identify more problems although consultations last longer. Patients who completed an agenda form were more satisfied with the depth of the doctor-patient relationship. Similar changes were observed in the number of problems identified and the duration of consultations if doctors were taught to explicitly deal with the patients' agenda. The combination of doctors' education about identifying the patient's agenda and patient completed agenda forms was associated with more problems being identified in consultations and longer consultations than for the interventions separately. Doctors require similar times (about five minutes) to deal with each problem whether or not patients have made their agenda explicit or if the doctor is trained in how to elicit the agenda. Neither intervention affects the likelihood of the patient raising further problems ("by the way" presentations) after the doctor considers the consultation finished.

Our study is methodologically strong as participants were randomly recruited and randomly allocated to the intervention arms and patients were randomly allocated to complete an agenda form or not. Patients were blind to the educational status of their doctors and to their allocated consultation. Patients were also recruited from a wide range of practices from inner city to rural areas. Our study had sufficient power to identify a difference of one minute in the time required to deal with a patient's problem. Nevertheless, the doctors were volunteers and we cannot assume that the findings apply to all doctors. Also, it was not possible to blind doctors to the interventions. These doctors may already have been identifying more problems in each consultation than the average doctor (1.7 compared with 1.2 problems $^{28}$ ). We acknowledge that data from the national morbidity study ${ }^{28}$ may not be comparable with data from our study but that even if our doctors were atypical, the interventions still increased the number of problems identified in each consultation. Thus although it is likely that the results are generalisable to patients, the response of doctors to a patient who brings an agenda form may not. The principle weakness of our study was that it was "open," so that doctors may have recorded more problems in agenda form consultations because of the non-specific effects of having a list presented and because consultations were timed by the doctors. Nevertheless, recording errors are likely to be similar in all the study arms. We therefore believe the study design to be strong and the findings robust.

A systematic review of observational studies of consultation length concluded that doctors who consult more slowly 
Table 2 Comparison of effect on consultation outcomes of using patient agenda forms or educating doctors to identify the patients' agenda, or both

\begin{tabular}{|c|c|c|c|c|c|}
\hline \multirow[b]{2}{*}{ Variable } & \multirow[b]{2}{*}{$\begin{array}{c}\text { No of } \\
\text { observations }\end{array}$} & \multirow{2}{*}{$\begin{array}{l}\text { Mean }(95 \% \mathrm{Cl}) \text { no education } \\
\text { plus no agenda form (reference } \\
\text { group) }\end{array}$} & \multicolumn{3}{|c|}{ Change in means $(95 \% \mathrm{CI})$ (reference group-intervention group) } \\
\hline & & & $\begin{array}{l}\text { No education plus agenda } \\
\text { form }\end{array}$ & Education plus no agenda form & Education plus agenda form \\
\hline $\begin{array}{l}\text { Duration of consultation } \\
\text { (minutes) }\end{array}$ & 902 & 7.1 (6.5 to 7.7$)$ & 0.9 (0.3 to 1.5$)$ & $0.7(-0.18$ to 1.6$)$ & 1.9 (1.0 to 2.8$)$ \\
\hline No of problems identified & 902 & $1.7(1.5$ to 1.8$)$ & $0.2(0.1$ to 0.4$)$ & $0.3(0.1$ to 0.6$)$ & $0.5(0.3$ to 0.7$)$ \\
\hline Time per problem (seconds) & 899 & 305.7 (276.8 to 334.5) & $-10.8(-39.1$ to 17.5$)$ & $-26.4(-67.0$ to 14.1$)$ & $-14.7(-55.2$ to 25.7$)$ \\
\hline General satisfaction & 857 & 83.6 (81.5 to 85.8$)$ & $1.4(-1.1$ to 3.8$)$ & $-0.3(-3.2$ to 2.7$)$ & $0.1(-2.9$ to 3.0$)$ \\
\hline Professional care & 857 & 83.7 (81.8 to 85.6$)$ & $1.0(-1.0$ to 3.0$)$ & $1.16(-1.4$ to 3.7$)$ & $1.2(-1.3$ to 3.7$)$ \\
\hline Perceived time & 853 & 80.0 (72.4 to 77.6$)$ & $1.7(-1.4$ to 4.7$)$ & $-0.1(-3.7$ to 3.4$)$ & $2.5(-1.0$ to 6.0$)$ \\
\hline $\begin{array}{l}\text { Depth of doctor-patient } \\
\text { relationship }\end{array}$ & 855 & 74.2 (71.7 to 76.7$)$ & 3.0 (0.5 to 5.6$)$ & $1.7(-1.7$ to 5.0$)$ & $2.5(-0.8$ to 5.8$)$ \\
\hline "By the way" presentations" & 892 & 1.00 & $0.7(0.4$ to 1.0$) \dagger$ & $1.2(0.7$ to 2.1$) \dagger$ & 0.9 (0.5 to 1.5$) \dagger$ \\
\hline
\end{tabular}

${ }^{*}$ Further problems raised when doctor considers consultation to be finished.

†Odds ratios: odds ratios $>1$ indicate an increase in odds of "by the way" presentations when compared with baseline (neither education or agenda).

prescribe less often, offer more health promotion, and achieve higher levels of patient satisfaction, although no data are available on the numbers of problems identified. ${ }^{29}$ Four intervention studies have been published in which patients were given longer consultations (AD Wilson, personal communication, 2005). These have produced variable results. The effect on consultation length was less than that hypothesised (one and 3.5 minutes, with expected increases of four and 10 minutes, respectively $^{3031}$ ) and, in one study, a doubling (from $11 \%$ to $22 \%$ ) of the number of consultations in which two or more problems were recorded. ${ }^{32}$ The observed durations of consultations in the control arm of our study was similar to that previously reported in observational studies of UK general practice but shorter than those in other countries, ${ }^{29}$ and the increase in consultation length was of similar magnitude to that of intervention studies that aimed for much greater changes in consultation length.

Although we used a variety of patient centred and doctor centred outcome measures, these are to some extent proxy measures of health outcomes. The effect the interventions will have on other health outcome measures such as duration of symptoms, health status, prescribing, or referral is uncertain but important. Similarly, it is unknown whether a more intensive educational package would have an effect on outcome. Finally, our study gives no information on whether the identification of additional problems in a consultation results in fewer future consultations.

If patients are encouraged to make their agenda more explicit by writing it down before the consultation, then general

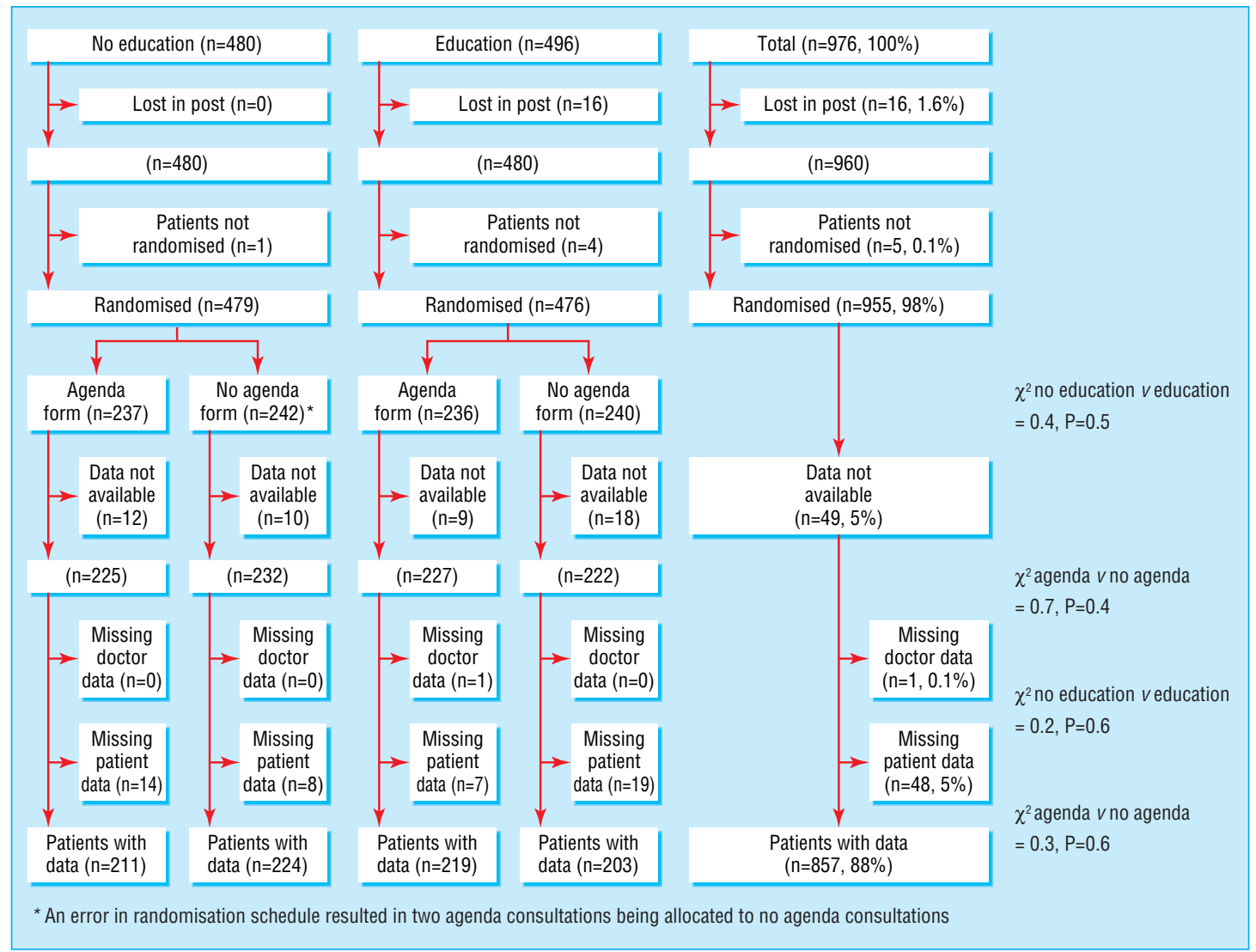

Fig 2 Availability of data between study groups 


\section{What is already known on this topic}

Answering the question "Why have you come to see me today?" is a key step in consultations, which is often not achieved

Asking patients to prepare for the consultation by writing down questions they want to ask improves some patient outcomes

\section{What this study adds}

Training doctors to elicit the patient's agenda or asking patients to write down what they want from the consultation increases the number of problems identified and may increase patient satisfaction even though consultations are longer

These interventions are not additive

These interventions may reduce the pool of unidentified problems during the consultation

practitioners will identify an average of four additional new problems for each consultation session of 18 patients, although the consultation session will take 19 minutes longer. Educating general practitioners about the patient's agenda will result in the identification of six more problems and the session will last an additional 13 minutes. The combined intervention will enable the identification of an additional nine problems but sessions will be 34 minutes longer. Although this represents an increased workload for doctors, it may also represent a potential pool of unrecognised need among patients which, with the introduction of a simple intervention, can be addressed.

We thank the patients and doctors who participated in this study. Contributors: JFM devised and designed the interventions. JFM and RKM designed the study, JFM recruited all practitioners, delivered the educational intervention, processed and checked the integrity of all data, carried out the preliminary analysis, and contributed to writing the paper. RKM supervised the research, devised the strategy for presentation of the results, and wrote the first draft of the paper. CLG advised on, and carried out, the statistical analysis and contributed to writing the paper, in particular, the statistical and results sections. JFM and RKM are guarantors.

Funding: Scientific Foundation Board of the Royal College of General Practitioners.

Competing interests: None declared.

Ethical approval: This study was approved by Leicestershire local research ethics committee.

1 Spence J. The need for understanding the individual as part of the training and function of doctors and nurses. In: National Association for Mental Health, ed. The purpose and practice of medicine. Oxford: Oxford University Press, 1960;271-80. Berger J, Mohr J. A fortunate man. London: Writers and Readers Publishing
Co-operative, 1976.

3 Byrne PS, Long BEL. Doctors talking to patients. London: HMSO, 1976.
4 Tuckett D, Boulton M, Olson C, Williams A. Meetings between experts: an approach to sharing ideas in medical consultations. London: Tavistock, 1985

5 Williams SJ, Calnan M. Key determinants of consumer satisfaction with general practice. Fam Pract 1991;8:237-42.

6 Cartwright A, Anderson A. General practice revisited. London: Tavistock, 1981.

7 Webber V, Davies P, Pietroni P. Counselling in an inner city general practice: analysis of its use and uptake. Br J Gen Pract 1994;44:175-8.

8 Maguire P, Faulkner A. Communicate with cancer patients: 1. Handling bad news and difficult questions. BMJ 1988;297:907-9.

9 Postlethwaite RJ, Lewis MA, Webb NJ, Eminson DM. Doctors as well as patients need education to ensure adherence to treatment regiments. BMJ 1997;314:755.

10 Stewart MA. Effective physician-patient communication and health outcomes - a review. Can Med Assoc J 1995;152:1423-33.

11 Hulsman RL, Ros WJ, Winnubst JA, Bensing JM. Teaching clinically experienced physicians communication skills. A review of evaluation studies. Med Educ 1999;33:655-68.

12 Evans BJ, Kiellerup FD, Stanley RO, Burrows GD, Sweet B. A communication skills programme for increasing patients' satisfaction with general practice consultations. $B r$ JMed Psychol 1987;60:373-8.

13 Kaplan SH, Greenfield S, Ware JE. Assessing the effects of physician-patient interactions on the outcomes of chronic disease. Med Care 1989;27:S110-27.

14 Greenfield S, Kaplan SH, Ware JEJ, Yano EM, Frank HJ. Patients' participation in medical care: effects on blood sugar control and quality of life in diabetes. J Gen Intern Med 1988;3:448-57.

15 Johnson JE, Nail LM, Lauver D, King KB, Keys H. Reducing the negative impact of radiation therapy on functional status. Cancer 1988;61:46-51.

16 Greenfield S, Kaplan S, Ware JEJ. Expanding patient involvement in care. Effects on patient outcomes. Ann Intern Med 1985;102:520-8.

17 Egbert LD, Battit GE, Welch CE, Barlett MK. Reduction of postoperative pain by encouragement and instruction of patients-a study of doctor-patient rapport. $N$ EnglJ Med 1964;270:825-7.

18 Thompson SC, Nanni C, Schwankovsky L. Patient-oriented interventions to improve communication in a medical office visit. Health Psychol 1990;9:390-404.

19 Middleton JF. Asking patients to write lists: feasibility study. BMJ 1995;311:34

20 McCann S, Weinman J. Empowering the patient in the consultation: a pilot study. Patient Educ Couns 1996;27:227-34.

21 Middleton JF. The patient's agenda. 1997. MD Thesis, University of Leicester.

22 Middleton JF. Successful consultations: the patients agenda. Mod Med 1991;Apr:183-6.

23 Middleton JF. Eliciting the patient's agenda: a workshop for general practitioners. Educ Gen Pract 1998;9:231-4.

24 Middleton JF, McKinley RK. General practitioners value the opportunity to develop their clinical skills. Educ Gen Pract 2000;11:307-11.

25 Ukoumunne OC, Gulliford MC, Chinn S, Burney PGJ. Methods for evaluating area-wide and organisation-based interventions in health and healthcare: a systematic review. Health Technol Assess 1999;3(5):27-32

26 Baker R. Development of a questionnaire to assess patients' satisfaction with consultations in general practice. BrJ Gen Pract 1990;40:487-90.

27 Baker R, Whitfield M. Measuring patient satisfaction: a test of construct validity. Oual Health Care 1992;1:104-9.

28 McCormick A, Fleming D, Charlton J. Morbidity statistics from general practice. Fourth national study 1991-1992. London: Royal College of General Practitioners, Office of Population Censuses and Surveys, and the Department of Health, 1995.

29 Wilson A, Childs S. The relationship between consultation length, process and outcomes in general practice: a systematic review. Br J Gen Pract 2002;52:1012-20.

30 Ridsdale L, Carruthers M, Morris R, Ridsdale J. Study of the effect of time availability on the consultation.J R Coll Gen Pract 1989;39:488-91.

31 Wilson A, McDonald P, Hayes L, Cooney J. Health promotion in the general practice consultation: a minute makes a difference. BMJ 1992;304:227-30.

32 Morrell DC, Evans ME, Morris RW, Roland MO. The "five minute" consultation: effect of time constraint on clinical content and patient satisfaction. Br Med J (Clin Res Ed) $1986 ; 292: 870-3$

(Accepted 16 March 2006)

doi 10.1136/bmj.38841.444861.7C

Leics, Northants and Rutland Deanery, University of Leicester

J F Middleton education consultant

Department of Health Sciences, University of Leicester, Leicester General Hospital, Leicester LE5 4PW

R K McKinley senior lecturer in general practice

$\mathrm{C} \mathrm{L}$ Gillies research associate

Correspondence to: R K McKinley rkm@le.ac.uk 